\title{
CONDIÇÕES DE TRABALHO E CAPITAL CULTURAL DE PROFESSORAS DE FILOSOFIA NO ENSINO MÉDIO
}

\author{
WORKING CONDITIONS AND CULTURAL CAPITAL OF PHILOSOPHY TEACHERS IN HIGH \\ EDUCATION
}

\section{CONDICIONES DE TRABAJO Y CAPITAL CULTURAL DE PROFESORES DE FILOSOFÍA EN LA ESCUELA SECUNDARIA}

\author{
Benedito Eugenio \\ Doutor em educação pela UNICAMP. Professor da Universidade Estadual do Sudoeste da Bahia e do \\ Programa de Pós-graduação em Ensino pelo PPGEn/UESB. \\ E-mail: dodoeugenio@gmail.com . \\ Orcid: . http://orcid.org/0000-0002-5781-764x
}

\author{
Wanessa Cristina Santos Prado \\ Mestra em Ensino pelo Programa de Pós-graduação em Ensino da Universidade Estadual do Sudoeste da \\ Bahia (PPGEn/UESB) \\ E-mail: eproinfowanessa@gmail.com
}

\begin{abstract}
RESUMO
Neste artigo apresentamos os resultados de uma pesquisa que objetivou compreender as condições em que se efetiva o exercício da docência para o professor de Filosofia de uma escola estadual baiana do ensino médio e como essas condições conferem posições sociais e implicam na construção do habitus professoral. Os dados foram construidos por meio de uma pesquisa qualitativa do tipo exploratória. O instrumento empregado para a produção dos dados foi a entrevista semiestruturada com duas docentes de uma escola pública de Vitória da Conquista-Ba. O referencial teórico empregado nas análises é a sociologia de Bourdieu. As conclusões apontam que mesmo com as dificuldades presentes e o desprestígio da docência, esta possibilita às professoras a ampliaçãodo capital cultural.
\end{abstract}

Palavras-chave: Condições de trabalho. Capital cultural. Ensino de Filosofia.

\section{ABSTRACT}

In this article we present the results of a research that aimed to understand the conditions in which the exercise of teaching for the Philosophy teacher of a Bahia state high school is effective and how these conditions confer social positions and imply the construction of the teaching habitus. The data were constructed through an exploratory qualitative research. The instrument used to produce the data was a semi-structured interview with two teachers from a public school in Vitória da Conquista-Ba. The theoretical framework used in the analyzes is Bourdieu's sociology. The conclusions point out that even with the present difficulties and the disrepute of teaching, this allows teachers to expand the cultural capital.

Keywords: Working conditions. Cultural capital. Philosophy teaching.

\section{RESUMEN}

En este artículo presentamos los resultados de una investigación que tuvo como objetivo comprender las 
condiciones en que el ejercicio de la enseñanza para el profesor de Filosofía de una escuela secundaria del estado de Bahía es efectivo y cómo estas condiciones confieren posiciones sociales e implican la construcción del hábito de enseñanza. Los datos fueron construidos a través de una investigación exploratoria cualitativa. El instrumento utilizado para producir los datos fue una entrevista semiestructurada con dos maestros de una escuela pública en Vitória da Conquista-Ba. El marco teórico utilizado en los análisis es la sociología de Bourdieu. Las conclusiones señalan que incluso con las dificultades actuales y el descrédito de la enseñanza, esto permite a los maestros expandir el capital cultural.

Palabras-clave: Condiciones del trabajo. Capital cultural. Enseñanza de filosofía.

\section{INTRODUÇÃO}

O retorno de Filosofia como disciplina ao currículo das escolas no Ensino Médio promove um debate sobre o papel da Filosofia na formação do estudante. Diversos estudos, desde 2009, vem sendo realizado sobre a temática. Em consulta à biblioteca digital de teses e dissertações (BDTD) da Capes empregando os termos "ensinode Filosofia”, “ensino médio”, “docência” localizamos 12 trabalhos dedicados à temática no período 2009-2019. Esse dado aponta para a importância de pesquisas sobre o ensino de Filosofia na educação básica.

Esta não foi a primeira vez que a disciplina de Filosofia faz parte dos currículos. Historicamente, seu início se deu com os religiosos da Companhia de Jesus, no século XVI. Com a Reforma Pombalina e os franciscanos, ela permanece no ensino das Universidades, no Brasil-colônia, passando por várias reformas e chegando no século XX como uma Filosofia que continua não refletir a realidade brasileira, tornada facultativa em 1964, retirada na reforma do ensino de $2^{\circ}$. Grau, Lei 5692/71. Em 1986 é recomendado o seu retorno.

Fomos constatando as nuances que a docência em Filosofia no ensino médio apresentava. Partimos do entendimento de que a divisão filosófica assumida pelo docente (agente) consciente ou inconscientemente, enquanto esquema de apreciação e julgamento - e onferido pela divisão de classe, segundo Bourdieu (2015) - no sistema de ensino, implica diretamente em sua prática docente.

Neste artigo apresentamos os resultados de uma pesquisa que objetivou compreender as condições em que se efetiva o exercício da docência para o professor de Filosofia de uma escola estadual baiana do ensino médio e como essas condições conferem posições sociais e implicam na construção do habitus professoral. 
O referencial teórico empregado é a sociologia de Bourdieu, particularmente seu conceito de habitus, entendido como sistema de disposições reconstruídas pelos indivíduos com base em suas experiências sociais. O sociólogo francês criou uma série de conceitos que nos permitem compreeender diferentes dimensões da vida social, como aponta a obra organizada por Catani (2017) e, como extensão, o exercício da docência, conforme veremos no decorrer deste artigo.

\section{Aspectos metodológicos}

Para a produção dos dados, utilizamos a pesquisa qualitativa do tipo exploratória. Segundo Flick (2009, p. 28), “o interesse dessa abordagem geralmente se concentra em desenvolver uma teoria a partir do material empírico e analisá-lo". A fluidez com que o fenômeno social pode ser manifesto exige um rigor que permita "entender a lógica de processos e estruturas sociais" (ALONSO, 2016).

Os dados foram construídos por meio de entrevista semiestruturada com 2 docentes, aqui nomeadas como Eva e Abigail , possuem mais de uma graduação. Ambas são graduadas em Pedagogia e Filosofia pela UESB. Bastos e Santos (2013, p. 39) afirmam que este tipo de entrevista em que se preocupa com a "construção de sentidos na interação (...) promove a re(construção) da realidade". Os critérios para inclusão das docents foram: a) formação específica em filosofia; b) exercício da docência em Filosofia no ensino médio.

As entrevistas, segundo Duarte (2004, p. 215), "são fundamentais quando se precisa mapear práticas, crenças, valores e sistemas classificatórios de universos sociais específicos, mais ou menos delimitados, em que os conflitos e contradições não estejam claramente explicitados". Dessa forma, a entrevista como um todo é uma construção da qual entrevistador e entrevistado participam ativamente. A entrevista semiestruturada mostrou-se um instrumento potente para entendermos o exercício da docência em Filosofia. Para a organização, utilizamos a análise de conteúdo.

A entrevista possibilita compreender o sentido prático produzido enquanto exercício docente, tendo em vista que a conduta dos agentes - exercício da docência - é resultado da incorporação das regras específicas do campo educacional, portanto, suas 
ações visam manter suas posições dentro do campo. Desse modo, partindo do pressuposto de que para Bourdieu teoria e prática são indissociáveis, a análise consiste em filtrar dessa relação teórico-prática "o produto do sentido prático" e do "sentido do jogo" do professor que ensina Filosofia dentro do subcampo do ensino de filosofia.

As entrevistas ocorreram no estabelecimento de ensino onde as professoras estão lotadas, uma escolar da rede estadual de ensino, localizada no município de Vitória da Conquista-Ba. Ambas as docentes assinaram o termo de consentimento livre esclarecido e a pesquisa foi aprovada pelo CEP/UESB.

\section{Condições de trabalho e ensino de filosofia no ensino médio}

Cunha (1999) adverte que não podemos confundir o trabalho do professor com o professor em situação de trabalho. Segundo a autora, o trabalho é concomitantemente "produto e produtor do professor, assim como este age igualmente nas suas definições de seu próprio trabalho" (CUNHA, 1999, p.213). Esse sentido primeiro expressa uma herança histórica, principalmente das influências Jesuíticas, porquanto, o exercício docente foi considerado uma espécie de comissionamento, o que justifica essa compreensão da profissão como um sacerdócio e acima de "interesses materiais”. Esse modelo deu lugar à concepção positivista de distanciamento ideológico "posições de mundo" que o professor deveria conservar. "Mais recentemente, o entendimento do magistério como semiprofissão adentra a compreensão crítica de que todo o trabalho está estruturado pelas relações de poder da sociedade" (CUNHA, 1999, p.214).

As influências das ideias neoliberais difundidas pela visão positivista de universalização e, consequentemente, de democratização do conhecimento por meio da escola também afeta a profissão docente, antes "prestigiada". Conforme o pensamento de Cunha (1999, p.214), se o acesso à “escola é para todos, sua qualidade é discutível”. A exclusão também advém da "proletarização" do magistério.

Diversos estudos já foram realizados acerca da condição de trabalho docente e trazem importantes contribuições para a compreensão do magistério, a exemplo de Fernandes (2019), Ludke e Boing (2004), Oliveira (2004), Gouveia et. al (2006), Nardi e Schneider (2014), dentre outros. Segundo Fernandes (2019, p. 52): 
professores é um tanto quanto complexa, uma vez que atualmente há diversas interpretações para o trabalho docente, ou seja, este tem sido alvo de constantes pesquisas que visam à caracterização do magistério no Brasil. Encontra-se na literatura a discussão sobre o tema a partir das categorias de pauperização, proletarização e precarização.

Uma das práticas de proletarização do magistério é o docente assumir disciplinas para as quais não apresenta formação. Conforme nos disse a professora Eva:

Não. Filosofia e, esse ano eu tô com filosofia e com História, mas já peguei sociologia, artes, educação física, rapaz... Depende da disposição da escola no momento, da disposição da carga horária.

Essa realidade, apontada na descrição da professora, não é exclusividade sua, mas condições em que são submetidos à maioria dos docentes. Tal proposição: “Indicador [...] proporção de docências com professores que possuem formação superior com a área de conhecimento em que lecionam na educação básica" (DOURADO, 2017, p. 137), constante na meta 15 do Plano Nacional de Educação, como evidenciado, não é novidade para as professoras, que foram compelidas por essa força externa conjectural, em momentos diferentes segundo conta Abigail: "a educação dos primeiros anos, dos anos, da educação básica era, a gente acaba ficando excedente no Estado, né? Aí falei 'não, vou fazer outro curso, vou fazer outra graduação'. Aí fiz filosofia no PARFOR”.

São essas as condições de trabalho experienciadas por muitos docentes na rede estadual de ensino na Bahia. O receio de ficar excedente na escola faz com que diversos professores assumam disciplinas para os quais não têm formação ou façam uma segunda licenciatura como possibilidade de permanecer na escola diante das alterções curriculares advindas da reforma do ensino médio.

Eva aponta que ser professor no Brasil apresenta algumas dificuldades, sendo a falta de reconhecimento e os baixos salários as principais delas:

Dificuldade no Brasil, a falta de reconhecimento, né. Primeiro, salário baixo, muitas turmas, muitos alunos por turma... Você tem que pegar muita turma pra fechar a carga horária. E de filosofia porque, como ela é uma disciplina que não tem no ensino médio, só nas escolas particulares, então muitos alunos chegam sem nem saber o que é. Aí a gente tem que, primeiro, sensibilizar, mostrar o que é, pra o aluno se apaixonar pela disciplina. E a maior dificuldade acho que é a falta de leitura de alguns alunos, mas, assim, particularmente, eles gostam bastante da aula de Filosofia.

A fala da professora sinaliza as dificuldades frente às condições de trabalho. De acordo com Sacristán (1999, p.83), é preciso dar-se conta que a atividade docente é gerada 
em "estruturas práticas [...] reprodutoras das regularidades nas quais foram geradas, requerem a presença e a sobrevivência de um passado que não está morto". O que queremos dizer ao utilizar as palavras de Sacristan é que não podemos desconsiderar o mundo social no qual o ensino de Filosofia se encontra. O professor filósofo que ensina filosofia (principalmente o iniciante) precisa reconhecer que sua prática, esteja ele consciente ou não, pertence a uma realidade de imposições "construídas pelas ações dos outros" e a participação do professor ocorre mediante "sistema de disposições duradouras" (BOURDIEU, 1996, p. 92).

Nesse cenário, vale a pena ainda considerar as políticas e propostas que afetam a escola, por intermédio de medidas adotadas para cumprir metas, como é o caso das avaliações externas. Da mesma forma, as reformas curriculares principalmente no ensino médio, o empresariamento da educação, o movimento escola sem partido, a tentativa constante da retirada das discussões de gênero dos currículos, as parcerias públicoprivadas, a entrada cada vez maior de grandes conglomerados educacionais na produção de material didático, dentre outros, impacta diretamente as condições de trabalho e a carreira dos professores.

Outro aspecto a considerar e que interfere nas relações dos professores com o currículo e as práticas educativas é que pouca preocupação do campo filosófico com relação às questões específicas do ensino na sala de aula. Analisando o currículo do curso de Filosofia realizado pelas docentes pesquisadas, identificamos uma desvalorização do ensino como subcampo da Filosofia. A prevalência é de disciplinas da chamada "Filosofia pura", que ocupa a maior parte do processo formativo. Do total de 2910 horas previstas na matriz curricular, apenas 480h foram destinadas a conteúdos didático-pedagógicos.

O curso realizado pelas docentes entrevistadas foi criado, segundo consta na apresentação do projeto pedagógico, com o intuito de atender uma demanda exigida pela Lei de Diretrizes e Bases artigo 36, parágrafo $1^{\circ}$, inciso III, "quando decreta a necessidade no domínio dos conhecimentos de filosofia e de sociologia necessários ao exercício da cidadania". O curso de Licenciatura em Filosofia destinado à Formação de Professores da Rede Estadual de Ensino apoia-se na necessidade da formação específica para atuar no ensino de Filosofia. A leitura do projeto permite afirmar que a proposta se fundamenta "no domínio dos conhecimentos de filosofia".

O projeto do curso propõe uma formação de professores de filosofia para Ensino 
Médio visando atender uma demanda conforme documentos oficiais, a exemplo das Diretrizes curriculares nacionais para a formação docente; Parecer CNE/CES 492/2001; Parecer 02, de 19 de fevereiro de 2002; Resolução CNE/CES número 12 e 13 de março de 2002; Parecer CNE/ 38, de 07 de julho de 2006; Resolução número 02 de 18 de junho de 2007.

O papel do curso é assim descrito: A graduação pretende contribuir na formação do profissional, munido de uma sólida formação filosófica, que o capacite para a compreensão, problematização e transmissão dos principais temas, tratados, problemas, sistemas filosóficos e reflexão crítica da realidade social e cultural em que se insere (UESB). O enunciado acima já revela a pouca preocupação específica com a formação docente. O projeto defende que o curso promova ao "licenciado habilitar-se-á a enfrentar os desafios à tarefa de despertar os jovens para a reflexão filosófica, problematizando junto aos alunos do ensino médio o legado da tradição e a importância do pensamento inovador, crítico, livre e independente" (UESB).

Com base nos paradigmas de formação de professores apresentados por DinizPereira (2007) e observando o projeto do curso de Filosofia e as entrevistas com as docentes, podemos afirmar que há uma alternância entre a racionalidade técnica e a racionalidade prática. O modelo da racionalidade crítica não foi identificado. Esses parâmetros nos levam a entender o sentido do habitus professoral presente na prática das professoras.

De acordo com Matos (2015, p. 17), na formação de professores de Filosofia há uma limitação curricular impingida aos docentes. Segundo ele: "os professores de filosofia foram formados em regime disciplinar e estão em sua maioria convencidos que o ensino de filosofia se justifica pela sua própria historicidade.” Essa condição perpassa pelo professor formador, formado na mesma "tradição".

As questões relacionadas ao exercício da docência não são contempladas na formação dos professores. Essas condições da formação docente repercutem diretamente no exercício da docência. Nossa pesquisa evidenciou que a professora Abigail cede aos pedidos dos alunos para contar história, escrever no quadro para que eles copiem ou mesmo das condições em que ele se encontram com o intuito de cumprir seu intento com as aulas de filosofia. Situação semelhante foi observada na prática pedagógica da professora Eva, que nos relatou que sempre tende a atender as demandas discentes para 
o Enem e o vestibular.

O que nos dá a entender como funciona a lógica do campo que ao conservar o privilégio da filosofia "pura", portanto ignorar a ação educativa, tratar-se de uma estratégia regulada por "princípios [schèmes] de percepção e de apreciação" (Bourdieu, 1996, p.) encontra inscrição na estrutura predisposta do professor filósofo que ensina filosofia.

Abigail aponta outras dificuldades em ser professor:

\begin{abstract}
Oh, meu Deus. Ser professor no Brasil eu acho que é muito - a grande dificuldade é justamente questão da estrutura, né? A estrutura, a questão de ser no Brasil, é por conta do nosso público. E, com todas as dificuldades, com todas as mazelas que tem na sociedade brasileira, ela vem também pra escola, vem também pra sala de aula. É dificuldade. Mas aí a questão do material, da estrutura mesmo, né? A questão da valorização da profissão de um professor hoje em dia, complicado. [...] A questão da falta do sentido de estar na escola [...] E de ser professora de filosofia no ensino médio, pra ser bem sincera, a maior dificuldade eu enfrentei esse ano, quando eu fui chamada de doutrinadora. Eu estou quase que, eu vou até para a justiça fazer uma denúncia porque teve um aluno que ele acabou convencendo outro grupo dentro da escola e ele me enfrentou mesmo, veio pra enfrentamento e ficou até meio perigoso pra mim.
\end{abstract}

Além do que já foi posto, a respeito do “cenário político vigente" (DOURADO, 2017, p. 23), há que se levar em conta que as políticas progressistas não estão voltadas para as condições do trabalho docente, nem para qualidade do ensino, como explicou a professora Abigail. Além das condições materiais, o desafio relatado pela professora Abigail retrata também o cenário da educação no sentido literal da palavra, uma vez que a educação ultrapassa a fronteira da escola e do professor como único responsável pela formação do estudante. Nesse sentido, há de se diferenciar o aspecto educacional (não formal) que é atribuído ao docente, mas não faz parte da função professoral, ou seja, o que lhe cabe: o ensino formal e sistematizado.

Essa concepção de ensino conducente institucionalizado da escola também tem a finalidade de conservar as diferenças sociais postas pela ordem vigente, por intermédio do isolamento. Particularizando o incidente vivenciado pela professora, seu relato alerta para o estado de isolamento do exercício docente. Esta condição do trabalho docente tem adoecido os professores por terem de realizar esses enfrentamentos sozinhos, muitas vezes, como no caso da professora, tendo que mobilizar ao seu modo os instrumentos legais para resoluções de problemas educacionais. Apesar de não detalhar como as outras 
instâncias da escola lidaram com o problema fica subentendido que não houve interferência por parte delas e, nem qual o motivo dessa ausência. Não fica claro se foi por omissão, "incapacidade" ou estavam alheias ao ocorrido.

O ensino de Filosofia vai além de "escolher" trabalhar o componente curricular numa perspectiva histórica ou temática. Há de se considerar sob quais condições objetivas são exercidas essa docência.

\section{As bases do capital cultural das professoras de filosofia}

O capital cultural é adquirido inicialmente no seio familiar e é legitimado na estrutura social no interior de um conjunto de conhecimentos e bens cultural reconhecidos socialmente. Esse capital, segundo Bourdieu (2000), apresenta-se dividido em três estados: a) incorporado: depende dos investimentos pessoais feitos pelo agente social no decorrer de seu processo formativo; b) objetivado: representado pelos livros, obras de artes. Só é possível reconhecê-lo se o agente social detiver instrumentos válidos para sua apropriação; c) institucionalizado: representado pelo diploma que o agente social detém para o exercício de determinada profissão.

De acordo com Carlindo (2014, p. 20), “a angariação de capital cultural enriquece a prática pedagógica ao facilitar o estabelecimento de relações entre conteúdos, conceitos, ideias e teorias que tornem mais fácil, para o professor, sua exposição e, para o aluno, seu entendimento".

Silva (2004, p.59), que a partir da teoria bourdieusiana desenvolveu o conceito de habitus professoral, discorrendo sobre o capital cultural de professores, aponta que este capital é:

[...] como um instrumento básico que possibilita a formulação dos modos do fazer didático alternativo para o ensino na sala de aula. O conteúdo amplia- se a partir dos recursos didáticos advindos do capital cultural, que oferece aos professores informações "técnicas" estruturais às explicações específicas que dão aos alunos, à formulação de exemplos, ao estabelecimento de relações com áreas afins, entre muitas outras coisas. Nessa medida, acredit[amos] que é do capital cultural adquirido pelo professor que vem a fertilidade das mediações criativas que implementam as especificidades dos conteúdos que ministra. [...] é dessa base de informações que a dimensão espontânea do fazer é alimentada.

Operacionalizar o ato de ensinar demanda a aquisição de capital cultural. Contudo, a posse desse capital em seus diferentes estados não é um processo simples. Podemos, 
por exemplo, ter um agente social com a posse do capital cultural institucionalizado e isso não refletir diretamente em seu capital cultural incorporado. Por isso, é importante identificar as formas pelas quais as professoras de Filosofia angariam esse tipo de capital. Isso só é possível conhecendo-as biograficamente.

Diferentes estratégias são empregadas pelos agentes sociais para a aquisição dos capitais (social, econômico, cultural, linguístico, simbólico), conforme apontam Carlindo e Silva (2017). Diante disso, práticas sociais, gostos, estilo de vida, linguagem, preferências e inclinações políticas são interiorizadas pelos agentes com base em suas disposições sociais. Todos esses elementos constituem o habitus do agente, isto é:

sistemas de disposições duráveis, estruturas estruturadas predispostas a
funcionarem como estruturas estruturantes, como princípio gerador e
estruturador das práticas e das representações que podem ser objetivamente
"reguladas" e "regulares" sem serem o produto da obediência a regras,
objetivamente adaptadas a seu fim, sem supor a intenção consciente dos fins e o
domínio das operações necessárias para atingi-los e coletivamente orquestradas,
sem ser o produto da ação organizadora de um regente.(BOURDIEU, 2003, p.54).

Dessa forma, o capital cultural familiar é imprescindível para o desempenho escolar dos filhos, pois é "ele que estimula e facilita a aprendizagem de conteúdos escolares e códigos considerados legítimos e impulsiona o êxito escolar" (CARLINDO, 2014, p.38). No caso de nossas professoras entrevistadas, mesmo que seus pais não tivessem escolarização formal e, portanto, capital cultural institucionalizado, reconheceram no investimento na escolarização um elemento importante para a aquisição do capital cultural incorporado.

Assim, as famílias investiram na escolarização de Eva e Abigail. Segundo Abigail:

Olha, eu entrei na escola, assim, bem diferente da minha família, com três anos de
idade eu fui para uma escolinha. Porque naquele tempo - eu sou a décima terceira
de uma família de dezoito filhos, então não tinha esse negócio com idade. Eu fui
morar numa cidade - eu morava na zona rural, então eu fui pra cidade, olha,
brincar com uma sobrinha que era da mesma idade que eu, mas, como eu era
grandona, então não se importaram muito com a idade e me mandaram pra essa
escolinha.

O capital cultural incorporado está relacionado ao corpo do agente, demanda tempo e investimento pessoal integrando-se, tornando-se habitus. Ele está "mais predisposto a funcionar como capital simbólico, ou seja, desconhecido e reconhecido, exercendo um efeito de (des)conhecimento, por exemplo, no mercado matrimonial ou no mercado de bens culturais" (BOURDIEU, 2015b, p.75)". Essa propriedade não pode ser herdada. Isso porque o possuidor do capital incorporado investe de si mesmo, tornando- 
se corpo e pagando com que lhe é "pessoal, o tempo". Por isso, é uma propriedade acumulada a despeito da família.

Por outro lado, "sabe-se que [...] a acumulação inicial do capital cultural útil - só começa desde a origem, sem atraso [...] pelos membros das famílias dotadas de um forte capital cultural". Contrariando essa perspectiva de "forte apelo à dependência do capital cultural" a respeito da idade correspondente a escolaridade as falas das professoras entrevistadas não atestam atraso escolar nos anos iniciais, incorrendo na categoria do improvável, da teoria bourdieusiana. Entretanto, o mesmo não se pode afirmar da formação ao longo do tempo conforme Bourdieu (2014).

Abigail desde cedo também tem acesso à leitura. Inicialmente apenas dos livros didáticos, tendo em vista que a escola não dispunha de biblioteca.

E que, pra minha salvação, quando eu estudava, era na segunda série, tinha livros da quarta série. E eu ficava na janela olhando a professora, a professora de quarta série lá, e tinha livro e tal - e depois essa professora me deu um livro de história, história infantil... Ela tinha um livro, me emprestou por muito tempo, acho que eu fiquei quase uns, mais de seis meses com esse livro. E os livros do meu irmão, que eu tinha um irmão que estava bem mais adiantado, então eu tinha livro didático mesmo. Eu lia livro didático, não tinha esses paradidáticos, não.

A professora Abigail nos informou que foi na Uesb, durante sua formação universitária, que pela primeira vez teve acesso a uma biblioteca. Segundo ela:

Não. Não, não. Oh, gente, eu vim conhecer uma biblioteca na UESB. Eu vim conhecer uma biblioteca na UESB, porque na minha cidade não tinha biblioteca. Hoje tem uma biblioteca, mas na minha época não tinha biblioteca. Quando eu cheguei na UESB, que eu me - eu não conhecia a UESB, eu só vim pra UESB estudar mesmo -, eu fiquei tão emocionada e eu, tipo, "meu Deus, eu não vou morrer sem ler um bocado desses livros”. [risos] Mas foi isso.

O contexto social da professora Abigail marca a sua trajetória de vida. Segundo Bonnewitz (2003, p.109), "as classes populares, cujo habitus é marcado pela escolha do necessário". Bonnewitz (2003, p.80), afirma ainda que "cada indivíduo é apenas uma variante de habitus de classe". Nesse sentido, a experiência da ausência de acesso aos livros é uma realidade social de recusa pela centralidade do aspecto da pequena burguesia, que é a "boa vontade cultural", enquanto a característica das classes populares é de “submissão à urgência” (BONNEWITZ, 2003, p.109).

Eva relatou ter contato desde a infância com livros: "Sim, muito. Minha mãe comprava bastante pra gente". Esse investimento econômico tem influência nas escolhas de cursos superiores que Eva fará posteriormente na universidade, todos ligados às 
humanidades e com alta carga de leitura, quais sejam, História, Pedagogia e Filosofia.

Com relação à leitura, Eva apontou:

Eu leio muitos livros de filosofia, romance, é. Filosofia, romance... Científico eu acho meio complicado. Educação também, eu leio muito livro de educação... Sim, leio. Então, eu leio muito livro de filosofia - alguns filósofos, alguns livros que trabalham algumas questões de filosofia. Leio clássicos de romance e educação também. Ultimamente tô lendo muito mais os romances.

A leitura realizada pelas professoras é uma forma de angariar capital cultural. Demonstra também investimento na profissão. Conforme retratado, também, na indisposição contida na expressão: "científico", ao referir-se as leituras de ficção científica. Segundo Bourdieu (2015b, p.42),

na realidade, cada família transmite a seus filhos, mais por vias indiretas que diretas, um certo capital cultural e um certo ethos, sistema de valores implícitos e profundamente interiorizados, que contribui para definir, entre outras coisas, as atitudes em face do capital cultural e da instituição escolar.

Abigail também revela que a leitura faz parte do seu cotidiano: "Leio com frequência, nós temos que estar lendo, né. Hoje eu tenho duas filhas, então, desde todos os conteúdos que tem da psicologia aí, às coisas, questões da atualidade, até os livros mais densos, e principalmente da área de filosofia. Agora mesmo eu estou lendo Diário de um subsolo".

A aquisição do capital cultural das professoras entrevistadas advem sobretudo das leituras e da consuta à internet, conforme quadro abaixo.

\begin{tabular}{|l|c|c|}
\hline $\begin{array}{l}\text { Capital cultural } \\
\begin{array}{l}\text { O exercício da docência } \\
\text { lhe possibilitou melhores } \\
\text { condições de vida? }\end{array}\end{array}$ & Eva & Abigail \\
\hline $\begin{array}{l}\text { Qual o seu tipo de leitura } \\
\text { predileto? }\end{array}$ & Filosofia Romance Educação & $\begin{array}{l}\text { Clássicos Formação } \\
\text { Revista: Jovem, Carta capital. } \\
\text { Temas: Financiamento Política, } \\
\text { Violência. Questões } \\
\text { existencialistas: livro Diário de } \\
\text { subsolo. }\end{array}$ \\
\hline $\begin{array}{l}\text { Você costuma viajar? } \\
\text { Você costuma ir ao } \\
\text { teatro? }\end{array}$ & Sempre & Às vezes \\
\hline $\begin{array}{l}\text { Você costuma ir ao } \\
\text { cinema? }\end{array}$ & Raramente* & Às vezes* \\
\hline Você lê com frequência? & Sempre & Às vezes \\
\hline & Sim & Sim \\
\hline
\end{tabular}




\begin{tabular}{|l|c|c|}
\cline { 2 - 3 } $\begin{array}{l}\text { quais são as leituras } \\
\text { preferidas? }\end{array}$ & $\begin{array}{c}\text { livros que trabalham algumas } \\
\text { questões de filosofia } \\
\text { Clássicos de romance }\end{array}$ & De: Questões da atualidade \\
\cline { 2 - 3 } & Educação & $\begin{array}{c}\text { Até: Livros densos } \\
\text { Pripalmente: área de } \\
\text { Filosofia }\end{array}$ \\
\hline $\begin{array}{l}\text { Quais as principais fontes } \\
\text { de informação? }\end{array}$ & Internet Jornais & Internet Revistas livros \\
\hline
\end{tabular}

O professor ocupa posições no espaço social. Segundo Penna (2008, p.559), "as condições objetivas nas quais o exercício docente se desenvolve e que, por sua vez, são fruto da institucionalização da função contribuem para a constituição de determinadas disposições integradoras de habitus relacionado a esse exercício que, entre outras formas, se expressam na prática docente".

A ampliação da escolarização trouxe a possibilidade da melhoria das condições de vida das docentes, o que corrobora os estudos acerca da mobilidade social nas camadas populares. Exercer a docência contribuiu diretamente para a elevação do capital cultural das professoras quando observamos sua origem social.

\section{CONSIDERAÇÕES FINAIS}

Neste artigo, tivemos como pressuposto que o habitus, um princípio gerador de práticas objetivamente classificáveis, ao mesmo tempo em que se constitui também em um sistema de classificação de tais práticas, observamos que as várias condições de existência produzem habitus diferentes que repercutem diretamente nos estilos de vida e nas práticas das professoras.

As condições de trabalho a que as professoras estão expostas precisam ser cada vez mais pesquisadas, conforme apontam estudos já realizados por outros autores que se dedicam principalmente ao campo da formação docente. Há uma relação direta dessas condições na construção da profissionalidade docente e do habitus professoral.

Mesmo com as dificuldades presentes nas condições objetivas em que as professoras desenvolvem seu trabalho e o desprestígio social da profissão docente, exercer a docência traz ganhos materiais e simbólicos que se expressam no habitus e, em última instância, se expressa em distinções no contexto da cultura escolar. 


\section{REFERÊNCIAS}

ALONSO, Ângela. Métodos qualitativos em pesquisa: uma introdução. Métodos de pesquisa em ciências sociais: bloco qualitativo. São Paulo: Cebrap, 2016.

BASTOS, Lílian C.; SANTOS, Willian S. dos. A entrevista na pesquisa qualitativa: perspectiva em análise da narrativa e da interação. Rio de Janeiro: Faperj/Quatet, 2013.

BONNEWITZ, Patrice. Primeiras lições sobre a sociologia de Pierre Bourdieu. Petrópolis; Vozes, 2003.

BOURDIEU, Pierre. Esboço de uma teoria da prática. In: ORTIZ, Renato. (Org.). A sociologia de Pierre Bourdieu. Trad. Patrícia Montero e Alícia Auzmendi. São Paulo: Olho D"água, 2003.

BOURDIEU, Pierre. Razões práticas: sobre a teoria da ação. 10 ed. Campinas: Papirus, 1996.

BOURDIEU, Pierre. Esboço de uma teoria prática. Porto: Celta, 2002.

BOURDIEU, Pierre. A economia das trocas simbólicas. 8 ed. São Paulo: Perspectiva, 2015.

BOURDIEU, Pierre; CHAMBOREDON, Jean-Claude; PASSERON, Jean-Claude. Ofício de sociólogo: metodologia da pesquisa na sociologia. 8 ed. Petrópolis: Vozes, 2015.

BOURDIEU, Pierre; NOGUEIRA, Maria Alice; CATANI, Afrânio. Escritos de educação. 16 ed. Petrópolis: Vozes, 2015.

BOURDIEU, Pierre. A distinção: crítica social do julgamento. 2 ed. Porto Alegre: Zouk, 2017.

CATANI, Afrânio Mendes (Org.).Vocabulário Bourdieu. Belo Horizonte: Autêntica, 2017.

CARLINDO, Eva P. Professores que atuam concomitantemente no setor público e privado de ensino no Estado de São Paulo: angariação de capital cultural. Tese (Doutorado em Educação). Araraquara: Faculdade de Ciências e Letras, Universidade Estadual Paulista, 2014.

CARLINDO, Eva P.; SILVA, Marilda da. Tornar-se professora: da incorporação de capital à estruturação do habitus professoral. Educação em Foco, v. 20, n. 30, jan/abr. 2017. p. 83104.

CUNHA, Maria I. da. Trabalho docente e ensino superior. In.: ALONSO, Oswaldo (Org.). Trabalho pedagógico. Porto Alegre: Sulina, 1999.

DOURADO, Luiz Fernandes. Plano Nacional de Educação: o epicentro das políticas de estado para a educação brasileira. Goiania: ANPAE, 2017. 
DUARTE, Rosália. Entrevistas em pesquisas qualitativas. Educar em Revista, n. 24, 2004. p.213-225.

FERNANDES, Anoel. Condições de trabalho de professores: reflexões conceituais e implicações para a docência. Revista Entreideias, Salvador, v. 8, n. 1, jan./jun. 2019. p. 51-70.

GOUVEIA, Andrea B. et. al. Condições de trabalho docente, ensino de qualidade custoaluno-ano. RBPAE, v. 22, n. 2, jul./dez. 2006. p. 253-276.

LÜDKE, Menga; BOING, Luiz Alberto. Caminhos da profissão e da profissionalidade docentes. Educação e Sociedade, Campinas, v. 25, n. 89, 2004. p. 1159-1181.

MATOS, Junot C. Formação de professors de filosofia: proposições para o debate. Eccos Revista Científica, n. 38, 2015. p. 31-41.

NARDI, Elton L.; SCHNEIDER, Marilda P. Condições de trabalho docente: novas tessituras das políticas de avaliação para a qualidade. Educação, Santa Maria, vol.39, n.1, 2014. p. 215228.

OLIVEIRA, Dalila Andrade. A reestruturação do trabalho docente: precarização e flexibilização. Educação e Sociedade, Campinas, v. 25, n.89, 2004. p. 1127-1144.

PENNA, Marieta G. Exercício docente na escola: relações sociais, hierarquia e espaço escolar. Educação e Pesquisa, São Paulo, v. 34, n. 3, set./dez. 2008. p. 557-569.

SACRISTÁN, José G. Poderes instáveis em educação. Porto Alegre: Artes Médica Sul, 1999. SILVA, Marilda. Metáforas e entrelinhas da profissão docente. São Paulo: Pioneira Thomson Learning, 2004.

Recebido em: 21/04/2020

Parecer em: 04/06/2020 Aprovado em: 06/12/2020 